\title{
12. Metric Melodies and the Performance of Sung Tales in the Hagen Area
}

\author{
Don Niles
}

\section{Introduction}

The purpose of this chapter is to convey some sense of the melodic and metric nature of Hagen sung tales through the examination of two related, but distinct, styles. Hagen (Melpa and Ku Waru) performances appear to stand as a subgroup separate from other regions particularly because of the metric binary melodies that provide a framework for the telling of the story (e.g., cf. Duna pikono as described by Gillespie and San Roque in chapter 3, this volume). ${ }^{1}$ I begin with what can be considered the most canonical of all Hagen performances, that by Paul Pepa from 1980. Aside from being recognized by Hageners as a superb performance, its status has been greatly enhanced by its repeated radio broadcast. It is also a particularly valuable example because Pepa's tale is preceded by a song, allowing me to identify some important elements of melodic style in this genre that are germane to the subsequent discussion of sung tales. I then consider other performers who have a very similar, if not identical, style of presentation to Pepa's.

In contrast, I then examine a related performance style found in the Ku Waru area of Western Highlands. While these are still definitely part of a Hagen subgroup of sung tales, there are also considerable differences in their melodic and metric realization.

\section{Paul Pepa's kang rom performance (Melpa)}

\section{Manda rop pora ndond. Nanga mbi Paul ni ka.}

I've finished my tale. I'm the one named Paul.

With these spoken lines, Paul Pepa (c. 1959²-2005; figures 1 and 4) concluded a sixteen-minute recording he had just made at Radio Western Highlands in Mount

\footnotetext{
1 I dedicate this contribution to the memory of Paul Pepa (d. c. April 2005) and Richard Alo (d. 28 January 2007). Both of them contributed in different, yet vital, ways to our project. I greatly valued their friendship, knowledge, and skills. They are very sorely missed, yet remain an inspiration to my work.

2 Information from Alan Rumsey (email, 20 March 2007) notes that when Rumsey first met him in 2003, Pepa said he was born in 1959. Pepa also told me the same date in 2004. Apparently born at the time of a major census in his area, he was given the name Pepa, the Tok Pisin word for 'paper', referring to the census forms used for recording information.
} 
Hagen. ${ }^{3}$ While the story Pepa told had ended, in many ways this recording and its subsequent broadcasts were pivotal events for the genre he had just presented in a masterful performance. Hence, his story also begins here.

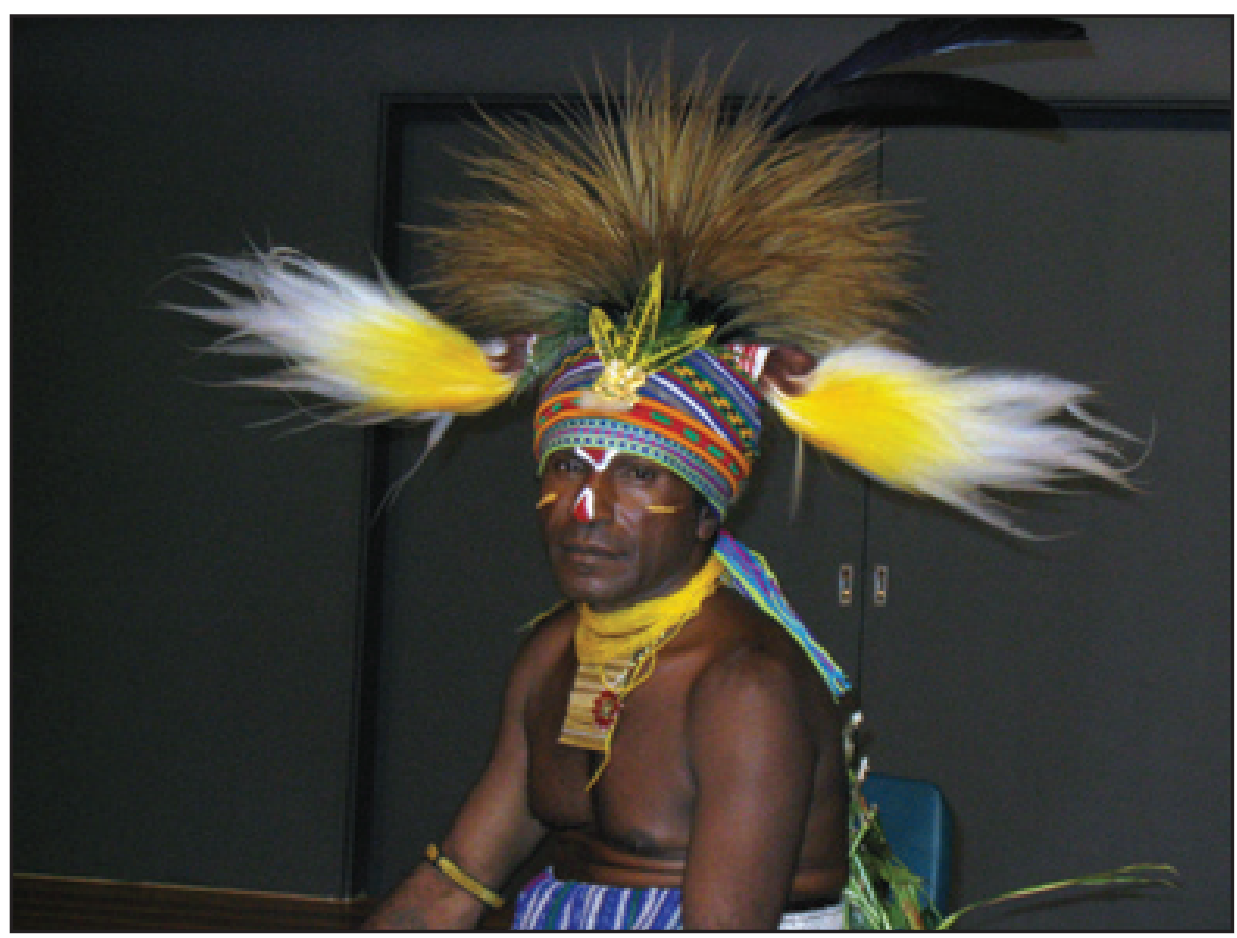

Figure 1. Paul Pepa, decorated as if for courting, before performing kang rom in Goroka, February 2004 (photo by author).

Pepa made this recording of a Melpa kang rom on Monday, 17 November 1980, when he would have been about twenty-one years old. While no recordist is listed on the box of the five-inch reel of tape, ${ }^{4}$ the typed label gives a short title, identifies Pepa as from Nengil in the Mul area, the duration of the recording, cataloguing number, and two lines suggesting that the recording was even felt at the time to be of some lasting importance: "tumbuna [Tok Pisin: traditional/ ancestral] stories to be kept ... please don't erase."

Shortwave radio broadcast began from Mount Hagen in 1966 at 250 watts, one year after the first Highlands station opened in Goroka, with both stations

3 For information about Pepa's recordings, I greatly appreciate the assistance of the station manager of Radio Western Highlands, Anna Pundia, who kindly had her staff locate the original tapes and cataloguing information for me in August 2006. In 2004, Pepa told me that he made his recordings in 1973, when he would have been about fourteen years old. However, 1973 is almost certainly incorrect, particularly since there are dates written on the tape boxes of the recordings held at the radio station.

4 In 2004, Pepa said that Kindi Lawi had recorded him at the radio station, but I have been unable to verify this, and Lawi's name is not written on the tape boxes of Pepa's recordings. During 1982-87, Lawi was the provincial Member of Parliament for Western Highlands. 
increasing power to 2 kilowatts in 1971 (Mackay 1976:173-74). The present building housing Radio Western Highlands or Nek bilong Tarangau (Tok Pisin: 'voice of the eagle') was opened on 15 January 1973. In common with all Papua New Guinea radio stations at the time, considerable effort was made to record music and stories from groups in the area. This would frequently involve radiostation officers attending traditional local events to do on-location recordings. Performers would also occasionally go directly to the studio to be recorded, as in Pepa's case. Such recordings were broadcast in special time slots devoted to traditional expressions.

As noted by Strathern and Stewart (2005a:29, n. 3) and Rumsey (2006b:330), Pepa's performances ${ }^{5}$ were broadcast frequently during the 1980 s, and these broadcasts were often recorded onto cassette for further listening. These significant "transplacements" of the traditional performance context (Strathern and Stewart 2005a:23) meant new relations between performer and audience, a much larger audience, and encouraged an identification of such a performance as standing for the Melpa, if not Western Highlands in general. Repeated broadcasts also meant that the traditional variations inherent to repeated performances of such an oral tradition were absent; instead, exactly the same performance could be heard repeatedly by a much larger audience than could ever traditionally gather in a house around the fire at night. Furthermore, the intimate traditional setting was replaced by one in which the performer and audience were invisible to each other. That this performance was frequently broadcast has not lessened its impact. Instead, it is still regarded very highly, setting a standard against which other performers continue to be compared. As such it is a perfect example to begin discussion of metric melodies in this region.

Pepa's recorded performance displays three examples of his abilities in oral expression: speech, song, and sung tale. A brief spoken introduction is followed by a song, all of which precede the kang rom. A very short spoken ending concludes the performance; it is transcribed and translated at the beginning of this section. The timings of the different sections and their relation to the whole performance are as follows:

5 On 31 March 1981 Pepa again went to Radio Western Highlands to record a kang rom. This, however, concerns the story of Kwint Wöp and Morokla Rakop (cf. Strathern and Stewart 2005b:224, n. 1, no. 5), and is in a different melodic and metric style, again using five-beat lines, but with twelve lines to a melody (see notation in Rumsey 2006b:331, fig. 3). Pepa's performance here lasts almost twenty-six minutes and was recorded by Bo George Kelly Kagl Wingti. Pepa's final kang rom were commissioned by candidates in national elections, most recently in the successful 2002 campaign by Paias Wingti where Pepa's kang rom was played over a public address system on a truck touring the province (Rumsey 2006a:58-59). For this composition concerning Wingti, Pepa used the melody requiring twelve lines of text, but it does not seem to be as widespread among other kang rom performers as the melody discussed in this paper. 


\begin{tabular}{lrr} 
& min:sec & percentage \\
\hline spoken introduction & $00: 22.7$ & $2.4 \%$ \\
song & $01: 11.6$ & $7.5 \%$ \\
kang rom & $14: 21.2$ & $90.0 \%$ \\
spoken ending & $00: 01.6$ & $0.2 \%$ \\
Total & $\mathbf{1 5 : 5 7 . 1}$ & $\mathbf{1 0 0 . 0 \%}$
\end{tabular}

\section{Spoken introduction}

In summary, Pepa's spoken Melpa prelude notes that he is about to tell a story from the past concerning a man named Krai from Miti and a woman named Rangmba from Ambra. ${ }^{6}$ Pepa further identifies himself and remarks that he is very good at telling such stories. Finally, he says that he will first sing a song, followed by the story itself. This introduction is characterized by relatively short bursts of very fast speech (lasting from 2.2 to $6.7 \mathrm{sec}$ ), separated by short breaths of less than a second.

Pepa never refers to the story he's about to tell as a kang rom. Instead, he consistently says kang teman or kanga teman, a generic term for 'narratives' combining $\operatorname{kang}(a)$, stories which are primarily seen as imaginative creations, and (ik) teman, which are generally felt to be more based on personal experience or historical events (Stewart and Strathern 2002:91-92).

\section{Song (amb kenan)}

A very brief breath follows the spoken introduction and precedes a song. While Pepa only refers to the song as a kenan - a generic term for a variety of songs that differ in performance context, choreography, decorations, and the gender of performers - everyone I have asked has readily identified it as an amb kenan courting song. Such songs are usually sung by a group of males who sit opposite couples of young men and women performing a seated dance known in Tok Pisin as tanim het. ${ }^{7}$ As will be described below, amb kenan structurally resemble many other types of dance songs. The text sung to the first statement of the melody is as follows: ${ }^{8}$

\footnotetext{
6 Miti hill is on a range separating part of the Central Wahgi plain from the Sepik-Wahgi Divide occupied by the Minembi tribe; Ambra, to the southeast of Miti, is a hill surrounded by swampy plains. Krai means 'love magic', Rangmba 'she/he will pluck/harvest'. See further discussion of these significant features in Stewart and Strathern (2002:115-16) and Strathern and Stewart (2005b:218).

7 For more detailed descriptions of such courting, see, for example, Stewart and Strathern (2002:47-48), Strathern and Stewart (2005b:202-3), and Niles (2007:110-13).

8 The Melpa text and English translation of Paul Pepa's performance derive from the excellent and tireless work done by Gomb Minimbi. Except for minor changes, I have followed her spelling of Melpa words and her translation of their meaning. I am unable to standardize these in accordance with other contributions here concerning Melpa performances, but since my focus is on musical features, I hope this is not too distracting. Nonetheless, I remain responsible for any misinterpretations of her work.
} 
1a. pa wai yo lde ro

moklken wi tömb ouil $e$ okla pön o lde ro

met kera kaimb ouil e mana wöin o lde ro

ku lde ro lde ro pa e ya

1b. pa wai yo lde ro

pren mong keng amb a kap kot o lde ro

ou po pakla mune a ruimpka nön a lde ro

ku lde ro lde ro pa e ya

\section{translation:}

1a. pa wai yo lde ro

you stay and go up the hills of Tömb o lde ro

come down the hills of Kaimb o lde ro

ku lde ro lde ro pa e ya

1b. pa wai yo lde ro

my well-built, flirtatious girlfriend o lde $r o^{9}$

you'll drink from the very tip of the pakla sugarcane a lde ro

ku lde ro lde ro pa e ya

Words in roman type are the meaningful or lexical text; italicized words are vocables, that is, without a lexical or grammatical meaning in normal discourse. However, within the context of song (and sung tales, as will be seen below), vocables have essential functions.

In the example here, lengthier series of vocables precede or follow the lexical text (e.g., pa wai yo lde ro; ku lde ro lde ro pa e ya), while only a few syllables of vocables follow one phrase of text (e.g., o lde ro) and a single vocable (e, a) appears between lines of text, e.g., "moklken wi tömb ouil $e$ okla pön." Consistently in this example, the textual section of the melody consists of two beats of text plus one of vocables, followed by one beat of text and two beats of vocables. Hence, vocables initially establish a melody, then may fill it out when the text is insufficient. In the present amb kenan, 70\% of the beats of the melody are sung to vocables, leaving the remaining 30\% to lexical text. Indeed some performers speak of the ease of composing a new lexical text, in contrast

9 Strathern and Stewart (pers. comm.. Oct. 2010) note that mong keng 'eye cheek' in the Melpa text refers "both to a girl who looks sideways in a flirtatious way and to the basic act in turning head, in which eyes and cheeks meet in a rolling action." I appreciate their fine-tuning of the translation of this line. 
to the difficulty of finding vocables for a melody. Although some songs consist entirely of vocables, most are a combination of vocables plus text. In the corpus examined to date, however, no song lacks vocables.

While the text of this song and the particular vocables used probably contribute to its identification as an amb kenan by listeners, its juxtaposition to the following kang rom concerning Miti Krai and Ambra Rangmba is also significant. Performances of amb kenan and kang rom usually belong to very different social occasions, so the combination of the two here is highly notable. Stewart and Strathern (2002:115) identify this kang rom story as "perhaps the most well known ... in Hagen. The two chief personae are the prototypes of couples who marry out of their own personal preferences, against the odds, and pay a price for doing so." Stewart and Strathern (2002:124-25, no. 3) also present a synopsis of the kang rom, fitting well with what Rumsey (2005:45) describes as the prototypical plot of Hagen sung tales:

a young man sets out from his home to court a young woman he has heard about in a far-away place, encounters obstacles, overcomes them, wins her hand, returns home with her, sometimes living happily and prospering with her help, and sometimes not.

Yet, this story is not restricted to kang rom performance, and may also be told simply as a kang narrative, that is, without employing the metric and melodic framework to be described below. Stewart and Strathern (2002:113-18) present a translation of and commentary on such a narration from 1964. However, even earlier published versions are found. Vicedom and Tischner (1943-48, vol. 3:15759; English translation in 1977:120-23) present a story concerning Waipa from Pundepukl and Raykopa from Koklne. ${ }^{10}$ In such stories, Waipa or Weipa are common substitutions for Krai, as is Raykopa or Rangkopa for Rangmba (Stewart and Strathern 2002:115; cf. 2002:124, no. 2, 125-35; Strathern and Stewart 2005b: 214-22). An even earlier version of a fragment of this story is given by Vicedom (1937:191-92), ${ }^{11}$ where the names of the protagonists are spelled using his earlier Melpa orthography as Bundibukc Waiba and Kokcnge Ranggoba. ${ }^{12}$ Here, Vicedom cites the story as the origin of the amb kenan courting dance. While it does not appear that the story can necessarily be described as presenting the origins of amb

10 While Strathern and Stewart (pers. comm., Oct. 2010) acknowledge a resemblance of themes between kang rom and the story presented by Vicedom and Tischner, they note that the "denouement ... is unlike kang rom, because Waipa's kin simply pay brideprice to Rangkopa's kin, and the two then live together at his place." This and other versions of the story (e.g., Stewart and Strathern 2002:113-18), leave "no doubt that spoken versions circulated and could have fed into the sung performances ... The initial kernel of the story does appear [in Vicedom and Tischner], but without the tragic portrayals of other versions, either sung or spoken."

11 I can find no mention of kang rom in any of the publications by the early missionary anthropologists in the Hagen area - Georg Vicedom, Hermann Strauss, or William Ross-however, it is possible that some of the stories they relate were told in this style.

12 Here and elsewhere in Vicedom's 1937 article, the digraphs $g c$ and $k c$ are used for velarized lateral sounds, which in Vicedom's later orthography (as found in Vicedom and Tischner 1943-48) are written as $\mathrm{gl}$ and $\mathrm{kl}$, respectively. 
kenan courting, all versions do describe the courting activities of the two characters. Hence, the identification of the song as a courting song and its placement before this particular story seem particularly apposite (also see Rumsey's discussion of the courting theme in sung tales in chapter 11, this volume).

The melody to which this text is sung can be divided into two halves (figure 2). ${ }^{13}$ The first half of the melody is partially tonally transposed a step lower in the second part. I have attempted to graphically show this and the structural use of vocables and text in the transcription. Note that although the two staves are joined together, they are not to be performed simultaneously - this obviously contrasts with the normal way of reading such notation. Rather, the top halfmelody is sung until the repeat sign and is then followed by the half-melody in the lower staff. This is indicated in the numbering of the verses: 1a, followed by $1 \mathrm{~b} ; 2 \mathrm{a}$, followed by $2 \mathrm{~b}$, etc. I have elsewhere called such melodies "binary melodies" to emphasize that the whole is made up of a particular type of pair; indeed the whole requires both parts for completion (Niles 2007:108). ${ }^{14}$

Figure 2. Amb kenan preceding Pepa's kang rom. An audio file of this example can be found in online item 19.

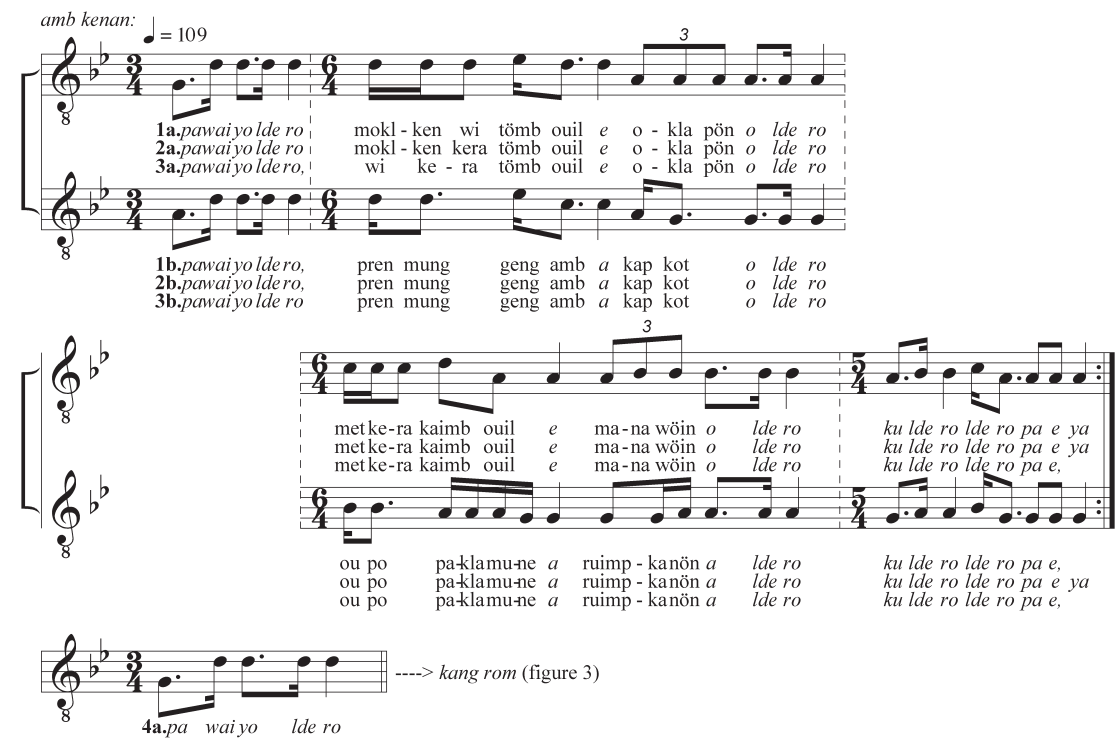

Barlines are rather arbitrarily drawn in figure 2, but have been included to show

13 The musical transcriptions in figures 2 and 3 are transposed up by a minor third to avoid the use of ledger lines and an overabundance of accidentals in the key signature, thereby resulting in the lower tonal centre to be on G. Hence, the opening G-D in the transcription is actually sung as E-B. Figure 6 is transposed downwards by a minor second for similar reasons. Note also that I use dashed barlines in transcriptions to indicate subdivisions of half-melodies.

14 The general importance of paired structures in Melpa thought is considered in Niles (2007:117). 
major structural divisions. And, while the tempo is rather rubato, a definite pulse can be detected. Both half-melodies contain the same number of beats, but the sustained pitches often differ by a step. For example, both half-melodies initially ascend to D using vocables; however, when the lexical text is sung, the sustained pitches of the first half-melody (i.e., the third of every three pitches) move $\mathrm{D}-\mathrm{A}-\mathrm{A}-\mathrm{B}$, before the final measure of vocables, while the corresponding pitches of the second half-melody proceed $\mathrm{C}-\mathrm{G}-\mathrm{G}-\mathrm{A}$. The final $5 / 4$ measure of vocables is tonally transposed down a step in the second half-melody. In broad outline then, the first half-melody begins by jumping G-D and gradually descends to conclude on A as tonal centre; the second half-melody beings on this same $A$ and jumps to $D$, then gradually descends to $G$ as tonal centre, the starting point again for the first half-melody.

Repetition of the entire two-part melody here involves an almost exact repetition of the vocables and lexical text as well. The only variation from that presented above is in the first line of lexical text. As noted above, initially it is: "moklken wi tömb ouil $e$ okla pön $o$ lde ro." This is changed in the second repetition of the melody to "moklken kera tömb ouil $e$ okla pön o lde ro," and in the third to "wi kera tömb ouil $e$ okla pön o lde ro." While the meaning of the first two versions is about the same- 'you stay and go up the hills of Tömb o lde ro'- the final version is 'you go up the hills of Tömb o lde ro'.

In order to simplify the musical transcription here and elsewhere, only the rhythmic divisions of the beat relevant for the first lines of text are shown. Subsequent lines sung to the same melodic fragment will subdivide the beat differently in order to accommodate a greater or lesser number of syllables.

Here the entire melody is repeated three times to conclude the amb kenan section. This is also fairly typical of amb kenan performances I have examined. However, while in this case one complete melody accommodates one complete statement of the text, in other songs this ratio varies: one statement of the text may require just one half-melody, or one-and-a-half, or even two statements of the full melody.

In figure 2, Pepa's breaths are marked with commas in the Melpa text. These breaths have also helped me decide where to draw barlines. His sung phrases (i.e., the sung lines of text, prefaced and terminated by breaths) are much longer than in his spoken introduction, averaging $11 \mathrm{sec}$, while his breaths take just less than a second. In this example, Pepa always takes a breath during vocables, never in the midst of lexical text. Occasionally, he drops a vocable to take his breath, omitting the final ya at the end of a half-melody.

I have discussed elsewhere in more detail how Melpa speakers distinguish between the words of a song (kenan mong 'song seed') and its melody (nuim kan 
'throat') (Niles 2007:115). Furthermore, the meaningful text is ik mong 'word seed', while vocables may be termed we ik, ik we (both meaning 'empty word'), or öi wöi (meaning unclear).

In summary then, the particular points I want to emphasize concerning this $a m b$ kenan are:

1. the text consists of a combination of vocables plus lexical text, with vocables used to fill out lines of melody when lexical text is insufficient;

2. the text is set syllabically to the melody;

3. the melody consists of two halves of equal length, with one half a partial, tonal transposition of the other at the interval of a step;

4. in each half-melody, vocables appear in the same position, but the text is varied;

5. sung phrases between breaths tend to be long, compared with spoken text;

6. the same two-part melody is repeated until the conclusion of the song, hence often involving complete, multiple repetitions of both the text and the melody;

7. the total duration of vocables in a melody often exceeds the total duration of lexical text;

8. while there is a definite, relatively slow, pulse to the melody, it is treated rubato, that is, with temporal variations;

9. although sung here solo, songs of all types are usually performed by a group who sing the text and melody in unison.

Most of these observations are true not just of this particular song, but of all Melpa songs, regardless of the genre concerned. Although the song occupies just over a minute of the entire performance considered here, this understanding of the typical sonic structure of Melpa song will help in appreciating what happens next, in the kang rom itself.

\section{Kang rom}

Following the conclusion of the third repetition of the two-part melody of the amb kenan, Pepa takes a slightly longer breath than he has up to this point $(1.1 \mathrm{sec})$ and then melodically, metrically, and textually starts a fourth repetition of the same song with the vocables pa wai yo lde ro (see bottom of figure 2). Immediately thereafter, the kang rom begins and will continue for over fourteen minutes.

Undoubtedly the most striking indicator of this change from amb kenan to kang rom, even for non-Melpa listeners, is the change in tempo. While the song has a pulse of about 109 beats per minute (bpm), the kang rom pulse begins at about $268 \mathrm{bpm}$ - that is, about two-and-a-half times faster - and will vary from c. 262 to $287 \mathrm{bpm}$ throughout the duration of the kang rom. And, in contrast to the 
rubato of the amb kenan performance, the kang rom appears to be quite regular, in spite of the very fast tempo. Indeed, the speed of the kang rom performance seems more similar to the pace of Pepa's introductory speech than to his courting song. Yet, like the latter, the text of the kang rom fits into a repeating melody of two equal halves.

Figure 3 outlines the structure of the kang rom melody and the beginning text. The text here is clearly divisible into "lines" of five beats. Each line is terminated by a vocable or, occasionally, a syllable ending in a vowel. But, in contrast to the preceding amb kenan, a vocable only appears at the end of a line. Eight such isometric lines are set to a binary melody. Hence, in contrast to the $70 \%$ of beats being devoted to vocables in Pepa's amb kenan, in the kang rom only a maximum of $20 \%$ of the beats is vocables: the sound of kang rom is heavily dominated by fast, meaningful text, structured into lines with terminal vocables sung to a repeating binary melody.

Figure 3. Melody of Pepa's kang rom. An audio file of this example can be found in online item 20.

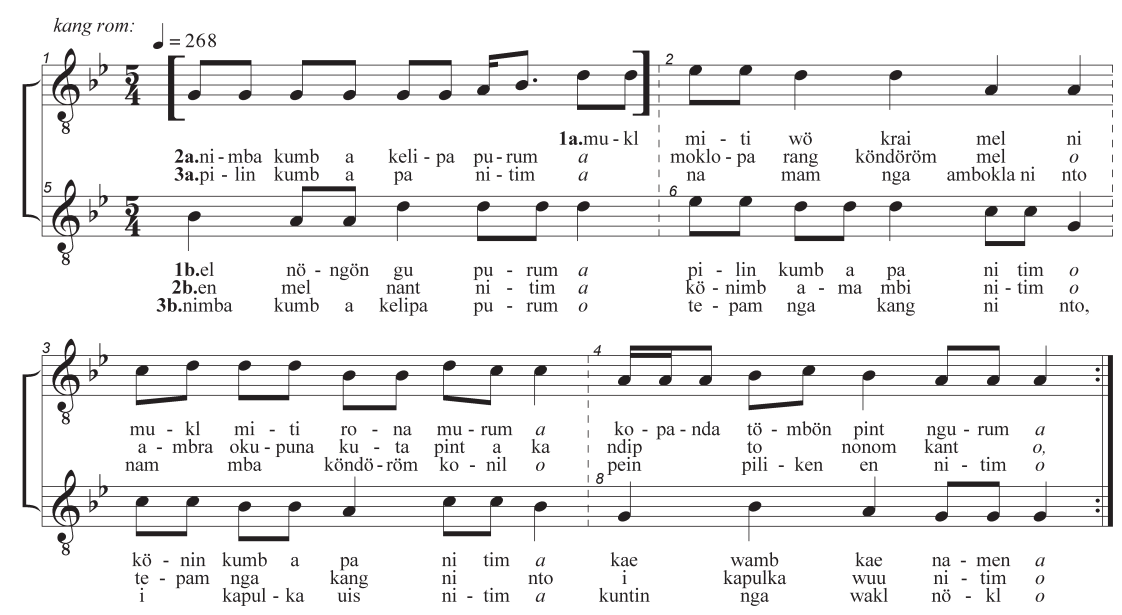

Interestingly, Pepa begins his kang rom on the last beat of the first measure of the melody - the beat usually devoted a vocable — with the word mukl 'mountain/ hill'. For this reason the first four beats of this measure are put in brackets in figure 3: their melodic and rhythmic values only become apparent in subsequent repetitions of the melody. The melody transcribed in figure 3 should be read as in figure 2, that is, the top staff is read until the repeat sign and then the bottom staff is read until the repeat sign, where the melody begins from the top staff again. However, while the amb kenan melody is repeated with only very minor melodic deviations from what is transcribed, there are more considerable melodic variations to be found in the repetition of the kang rom melody. The melody in figure 3, therefore, serves to provide the general shape of the melody, 
highlighting important pitches, but is not reproduced in exactly that form upon each repetition. In spite of this caveat, the melodic shape of this melody is strikingly similar to that of the preceding amb kenan.

The text and translation of the lines presented in figure 3 are as follows:

1a. mukl

miti wö krai mel ni

mukl miti rona murum $a$

kopanda tömbön pint ngurum $a$

1b. el nöngön gu purum $a$

pilin kumb pa nitim $o$

könin kumb pa nitim $a$

kae wamb kae namen $a$

2a. nimba kumb kelipa purum $a$

moklopa rang köndöröm mel $o$

ambra okupuna kuta pint ka

ndip to nonom kant $o$,

2b. en mel nant nitim $a$

könimb ama mbi nitim $o$

tepam nga kang ni nto

i kapulka wuu nitim $o$

3a. pilin kumb pa nitim $a$

na mam nga ambokla ni nto

nam mba köndöröm konil $o$

pein piliken en nitim $o$

3b. nimba kumb kelipa purum $o$

tepam nga kang ni nto,

i kapulka uis nitim $a$

kuntin nga wakl nökl $o$

\section{translation:}

1a. the man named Krai from Miti mountain

lived on top of Miti mountain 
like a tömbön spear moving forward

1b. like a nöngön arrow with blunt barbs

"let's hear about it and

see," they said

"who are these nice people?"

2a. he said and finished his talk

on top of the mountain he looked to the east

to the sweet potato plantation of Ambra valley

"I see a fire is coming up"

2b. "what's happening there?

I must go and see"

his father said "it's fine with me"

3a. "let's hear about it," he said

his mother said

"none of us ever go to that place

where do you want to go?"

3b. she said and finished her talk

but his father said

"it's fine with me"

his kuntin stone axe $\mathrm{e}^{15}$

Vocables are again italicized in the vernacular text, but are here omitted from the translation. Because of their regularity in delimiting a line of text, these vocables perhaps also allow the performer a brief rest and chance to mentally compose his or her thoughts for the next line. As has been demonstrated by Rumsey (2007) for the similar Ku Waru sung tales, each beat tends to be associated with a single word or bound morpheme, and each line terminated by a vocable tends to comprise a single syntactic unit.

15 This line belongs textually with what follows, rather than with the preceding lines shown here, i.e., "his kuntin stone axe he pulled towards himself and went outside the house'. This illustrates the fact that a complete statement of a melody or half-melody in performance does not necessarily coincide with an integral unit in textual or thematic terms (as is generally the case in Western notions of "verse" or "stanza"). In this short textual example, notice how a particular theme extends over statements of half-melodies: 1a-1b, 1b-2a, 3c-3b. The freedom for a composer/performer to focus on the creation of a poetic text is probably greatly assisted by the unceasing repetition of melodic and metrical features. Rumsey (2007:249) has found that there is a tendency, but not a rule, for correspondences between melodic units and textual ones in some of the Ku Waru performances he has examined. I certainly agree with him that this question needs be explored in greater detail. 
Occasionally, an additional syllable occurs in the text of figure 3 where none appears in the text translated above. For example, the second line of $1 \mathrm{~b}$ is written above as "pilin kumb pa nitim $o$," while the music example has "pilin kumb a pa nitim $o$. ." While the additional "a" could be considered a vocable, such additions are only used sparingly and never with any regularity within lines of text - that is, they do not occur at the same metric position in repetitions of the melody. They appear to be added to pad out a line of text that otherwise would not have a sufficient number of syllables to meet the metric requirements for a line. Frequently, but not consistently, this occurs between a word ending in a consonant and a following word beginning with one. These additions may be somewhat akin to epenthetic vowels.

The perfect fifth leap (G-D) concluding the amb kenan and prefacing the kang rom is precisely the melodic distance covered in the first measure of the kang rom. Pepa's transition from amb kenan to kang rom is melodically seamless. Yet, as noted above, Pepa only begins this measure on the last beat. While the melodic movement is of a perfect fifth, the beginning part of the measure is filled with vocables, the last beat with lexical text: a reversal of the common structure of Pepa's kang rom lines in this performance. The first half-melody then moves $\mathrm{A}-\mathrm{C}-\mathrm{A}$ on the final beats of each measure (measures 2-4).

The second half-melody begins with a jump from A to D (measure 5), then the finals of each measure are $\mathrm{G}-\mathrm{B} b-\mathrm{G}$ (measures 6-8). As in the amb kenan, much of the second half-melody is a tonal transposition of the first half-melody downwards by a step.

The length of Pepa's sung phrases is even greater than in the preceding song. Here they average $13 \mathrm{sec}$ in length, with the longest phrase over $16.5 \mathrm{sec}$. These phrases are separated by breaths averaging about a half of a second. Such long phrases are kept up throughout the duration of the performance and are certainly one of the outstanding features of Pepa's style, in contrast to most other performers examined to date.

In Pepa's performance, 63 such phrases contain 780 lines of text, involving over 97 repetitions of the eight-bar melody. Pepa only breathes at the end of bars, perhaps dropping the final vocable or even part of the preceding beat, when that text could easily be filled in by the listener. He also appears to have definite preferences about where in the melody to breathe. His breaths occur in positions such that when he resumes, he tends to begin on the third measure (16 times or $25.4 \%$ of the whole) or on the first, fifth, or seventh measures (each 11 times or $17.5 \%$ ) - note that the first and fifth measures, and the third and seventh measures are corresponding measures in each half-melody. In contrast, the other bars much less often begin a sung phrase: the second and sixth measures 
at $7.9 \%$ (5 times) and 9.5\% (6 times), respectively, while the fourth and eighth measures at 3.2\% (twice) and 1.6\% (only once), respectively, are very rarely used in this way.

In general then, Pepa continually repeats the eight-bar melody until he finishes his story. When he breathes, he begins again at the appropriate place in the melody. His performance is characterized by a very fast tempo, with long phrases between breaths. Yet, even though the melody is repeated over and over, deviations do occasionally occur, even with such a master storyteller. It can be particularly enlightening to look at these exceptions to the generalizations, for they make further revelations about the performer and his performance.

Beginning his twentieth sung phrase of the kang rom (at 5:47.1 in the performance; see online item 21), Pepa only sings two lines of text (to measures 2-3 of the melody), by far the fewest number of lines per breath phrase in his entire performance. After a slightly longer than average breath, he exactly repeats these two lines of text and the two measures of melody, and then continues on with another seven new lines of text to the appropriate measures of the melody.

Something similar happens at the second deviation from the norm, just a few phrases after the one described above. Pepa's twenty-fourth sung phrase (at 6:37.5 in the performance; see online item 22) is again shorter than normalonly seven lines of text - and the tempo here drops to c. $262 \mathrm{bpm}$. The last line is sung as $i$ kapulka wuu is, instead of its expected form $i$ kapulka wuu nitim a. Pepa has apparently run out of breath. This text is followed by what is by far the longest breath pause in the whole performance $(2.4 \mathrm{sec})$, Pepa then repeats the text and melody of the final two lines of the previous phrase (here, using the expected form of the line $i$ kapulka wuu nitim a), consequently beginning the phrase on measure 8 of the melody - the only phrase in the entire performance to do so. He then adds another eleven lines to this phrase before pausing again for breath. However, this twenty-fifth phrase shifts the entire melody a minor third higher and begins at a faster tempo (c. $278 \mathrm{bpm}$ ). For the five minutes since the beginning of the kang rom, Pepa has been very consistent in maintaining the pitch levels of his melody, with only a gradual slight lowering of pitches over this period of time. The newly established tempo and pitch level will remain until the end of the performance, that is, for about nine minutes. This transposition of the melody is extraordinary, considering the many faithful repetitions Pepa had done up until this point. And why is there such a long pause before this transposition? One wonders if the tape recorder may have been turned off while Pepa caught his breath or organized his thoughts. Then, when it was turned on again, Pepa repeated two lines of the previous phrase, but at a higher pitch level. Since there is no audible noise on the recording at this point, this must remain only conjecture. 
The final deviation can probably be termed a real error on Pepa's part, in contrast to the two previous examples that might be better considered corrections than mistakes. Pepa's fifty-first sung phrase (at 13:12.3 in the performance; see online item 23) concludes on the first measure of the melody, but in the jump of the melodic perfect fifth, his voice breaks on the higher note. After his breath, Pepa should begin with the second bar of the melody. Instead, he repeats the last textual line of the previous phrase, but uses the melody of bar seven. If this deviation would have been comparable to the two described above, Pepa would have repeated the textual line using the first measure of the melody. Here, however, he either backs up or jumps forward too far melodically. Seemingly unfazed by this error, Pepa sings another eleven phrases, all properly aligned to the repeating melody, to conclude his performance. His last phrase of the kang rom breaks into speech in the final line. And, after a final short breath, Pepa concludes: "I've finished my tale. I'm the one named Paul."

In considering what has been discussed here about Pepa's kang rom with the particular features listed above concerning his amb kenan performance, features nos. 1-5 are also true for his kang rom. However, note that in relation to no. 1, there is only one vocable per line. Nevertheless, it is of tremendous structural importance in delimiting the line metrically, melodically, and syntactically. Feature no. 6, concerning the repetition of the melody until the end of the performance, is also found in kang rom, but there is never a complete repetition of the entire text for the latter, although there are many repetitions of lines and much parallelism involved. While a song text may consist of a few lines of text sung to the same melody lasting a few minutes, a typical kang rom involves many hundreds of such lines. Thus, performers can "overwhelm the audience with a ceaseless flow of sound that keeps their attention focused upon the story and makes them see and hear it happening in their own minds as the performer does in his or hers" (Rumsey 2005:53). Indeed, I would suggest that such repeating metric melodies provide an ideal framework for such presentations: neither the audience nor the performer is distracted by unexpected metric or melodic sequences, encouraging a total focus on the story. Furthermore, such melodies are the expected framework for other sung performances. Feature nos. 7-9, however, are not found in Pepa's kang rom. Here the vocable is only one beat in a five-beat line, and the pulse is very fast. While there are certainly temporal variations, the pulse and pace of the performance is so fast that they are much more difficult to discern. Finally, kang rom is always a solo performance. Aside from many other factors, the very nature of sung tales as being composed in performance, regardless of various repeated elements, would make them impossible for group performance. 


\section{The canonical status of Pepa's performance}

The frequent broadcast of Pepa's kang rom over Radio Western Highlands in the 1980s brought a performance that would traditionally have been heard by only a small group of people in a house at night to a much larger audience. As the size of the audience increased, so did its diversity, bringing the performance not only to people who had never heard of Pepa, but also to people who spoke different languages or dialects than the Melpa used in his performance. While Melpa is spoken by the largest group in Western Highlands Province and has some prestige attached to it because of its use around Mount Hagen town, Pepa's masterful, oft repeated performances encouraged at least some Ku Waru speakers to prefer to perform their sung tales in Melpa, "due in no small measure to the popularity of one performer in particular, a Melpa man called Paul Pepa, who for many years has been esteemed throughout the western highlands as the greatest living practitioner of this genre" (Rumsey 2001:220, n. 9).

One $\mathrm{Ku}$ Waru performer, Paulus Konts, learned to perform sung tales from listening to Pepa's performance described above, but never met him until 2004 when both were featured performers at a workshop in Goroka (Rumsey 2006b:330; figure 4). Initially, Konts had only performed sung tales in Melpa (in which he was fluent, like many Ku Waru speakers), but following Rumsey's request, Konts began composing in $\mathrm{Ku}$ Waru, after just one day's practice (ibid.:330, n. 26). Today, Konts has composed many stories in $\mathrm{Ku}$ Waru as sung tales, using the same eight-bar melody (as learned from Pepa's performance) for all of them (ibid.:327). As noted above, Pepa only breathes at the end of lines in his performance and has definite preferences over where in the melody he does so. In one performance recorded and analysed by Rumsey, Konts's breathing is even more predictable than Pepa's, always occurring at the end of the fourth and eighth lines (Rumsey 2001:212). ${ }^{16}$ Another Ku Waru performer, Peter Kerua, also learned Pepa's melody and an early attempt of his in this style was recorded in 2004. Since his youth, however, Kerua has been performing in a different style, to be considered below.

Other performers have also been highly influenced by Pepa's recordings; some have even learned to perform kang rom from them. Andrew Strathern notes a young Melpa man named Ketepa Rongnda "learning to master the difficult art of performing song epics ( $k$ ang rom) by listening to cassettes of a performer who has become well known through broadcasts on Radio Hagen" (Strathern 1983:80). The unnamed performer is certainly Paul Pepa. Paul Palam (or Palyim), a Melpa man, performed a kang rom of the same story to the same melody as Pepa's during the 2006 Kefamo workshop concerning sung tales. He also claims

16 Owing to an obvious typo in a later paper, it is incorrectly stated that Konts breathes at the end of the fifth [sic] and eighth lines (Rumsey 2005:52-53). 
to have learned this style from Pepa's recording. The same melody and story were also used in a performance by a young man named Miti in Kiltkayake in 1982, recorded by Andrew Strathern and me. In this case, however, it is not clear whether his use of story or melody was influenced by Pepa's broadcasts.

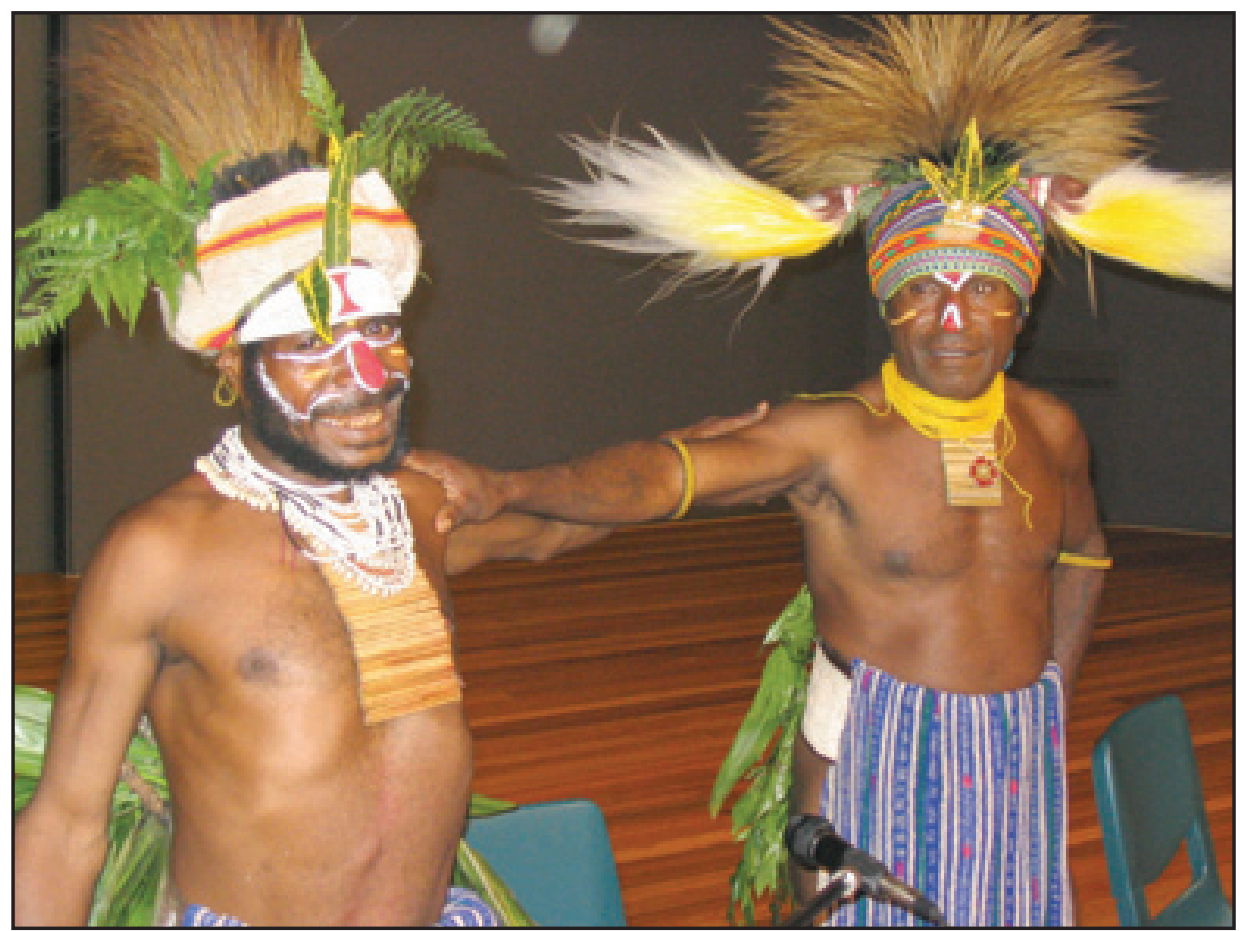

Figure 4. Paulus Konts (left) with Paul Pepa, both decorated as if for courting, at the Chanted Tales Workshop in Goroka, February 2004 (photo by author).

These examples should not be taken to suggest that either the story or the melody belongs to Pepa alone. Quite to the contrary, as noted above and as discussed by Rumsey in chapter 11, the story of Miti Krai and Ambra Rangmba and similar ones with differently named protagonists (Weipa or Waipa and Rangkopa, Ranggoba, or in the $\mathrm{Ku}$ Waru area, Tangapa) ${ }^{17}$ form part of a widespread oral tradition in the Hagen area, and have been recorded in various forms (as narrated kang and as kang rom sung tales) for over seventy years. Hence, Pepa's choice of story has wide-ranging relevance in the greater Hagen area as well.

Other melodies are also employed by Hagen performers (as is the case for Pepa himself), but most can definitely be considered binary melodies in the sense discussed above, and also contain lines ending in vocables. A varied form of Pepa's five-beat, eight-bar binary melody is found in performances by OkeKorpa of Kelua (Central Melpa) and Engal Ok Puluyl (Ku Waru area). Korpa’s

17 In a version by Konts, analysed by Rumsey (2001:213-14; 2005:60-64), the male protagonist is only identified about halfway through the story as the performer himself. 
performance of the story of Miti Weipa and Kundila Rangkopa was recorded in 1965 by Andrew Strathern, apparently the first audio recording made of a kang rom. Considerable analysis of the poetry of this performance has been published (e.g., Stewart and Strathern 2002:125-35; Strathern and Stewart 2005b:214-22; chapter 13, this volume). Rumsey recorded Ok Puluyl's performance in 1997 as part of a series of recordings from the Kaugel area. Ok Puluyl tells of the life and death of Jesus (Rumsey 2001:201; 2005:46). In both Korpa's and Ok Puluyl's performances, the melodies used are quite similar to Pepa's, but distinctively the final pitch of each bar (that which usually sustains a vocable) is held for two beats instead of one, thus resulting in a six-beat line for the eight-bar melody. According to different performers and the different melodic styles employed, line length appears to vary from five to eight beats per line. And the number of lines per melody varies between eight, ten, and twelve. There are also possible examples of four or sixteen line melodies, but analysis is still preliminary at this stage.

The story of Miti Krai and Ambra Rangmba can also be told using a completely different melody. In a recording again made at Radio Western Highlands, Kraip of Gumants (Dei Council), presents his story in a very fast monotone with only occasional (and, apparently, unpredictable) pitch deviations above or below. While Kraip's lines appear to contain five beats with a terminating vocable, initial analysis has not revealed a binary melody or any other type of repeating melodic structure - presently a unique sonic structure in the Hagen area.

Hence, Pepa's use of a well-known story told to a melody apparently with some currency in Melpa kang rom performances, the brilliance and clarity of his rendition poetically and musically, and its repeated transmission via radio and cassette all combined to produce a classic performance, which continues to transfix listeners and challenge performers today.

At the 14 February 2004 opening of the Goroka workshop concerning sung tales, Paul Pepa (then c. 45 years old) performed a short extract of this same kang rom, lasting just over three minutes. He still performed at a very fast tempo (c. 282 bpm) and with very short breaths between phrases. However, the lengths of his sung phrases averaged eight-and-a-half seconds, and some were as short as five seconds. Nevertheless, he still managed to extend some phrases over thirteen seconds. Twenty-four years had passed since his canonical recording at Radio Western Highlands, but his amazing abilities were still very much in evidence. 


\section{Peter Kerua's tom yaya kange performance (Ku Waru)}

Generalizing about melodic variability in the corpus of sung tales he has recorded in the $\mathrm{Ku}$ Waru area, Rumsey observes that some

performers use a four-line melody more-or-less like the first half of Koj's [Konts's], but mainly or entirely in glissando (i.e., with pitch movements that are continuous rather than alternating among discrete pitch levels). (Rumsey 2001:214; 2005:53)

Rumsey has also examined a sung tale performance by Kopia Noma. Noma's performance is characterized by lines of six beats (with a vocable on the final beat), sung to a binary melody requiring ten lines, and with melodic ascents corresponding to melodic descents at various points. Melodic transcriptions of this performance appear in Rumsey (2006b:340, fig. 4) and Niles (2007:109, ex. 1). ${ }^{18}$ An earlier recorded version of this story, told in Melpa by Noma and using the same melodic and metric structure is also analysed by Rumsey (1995:111-13).

Furthermore, Rumsey identifies vocable placement as a crucial component in the setting of a text to a melody in sung Ku Waru tales:

The added line-final vowel is one thing that all performers in my sample make use of. Many ... also use a second added vowel at a regular position within the line, usually after the third foot [or beat] if the line is rhythmically regular. This added vowel often has a pitch rise on it matched by a corresponding fall on the final added vowel. (Rumsey 2001:214-15; 2005:53; italics in original)

My discussion now focuses on a melodic type containing many of the characteristics noted by Rumsey, that is, pitch movements are more "continuous," pitch levels are less discrete, lines have a rise-fall alternation in pitch at a number of different structural levels, and recurring midline vocables are used in addition to line-final ones.

In the $\mathrm{Ku}$ Waru area, sung tales are called tom yaya kange (see chapter 11). As noted earlier, while some performers have adopted a melodic and metric style based on Pepa's performance, other styles are more prevalent, particularly in places less in contact with Melpa speakers.

18 The complete Ku Waru text and English translation of Kopia Noma's performance are given by Rumsey (2001:228-38), who also analyses it in considerable detail (ibid.:205-11). 


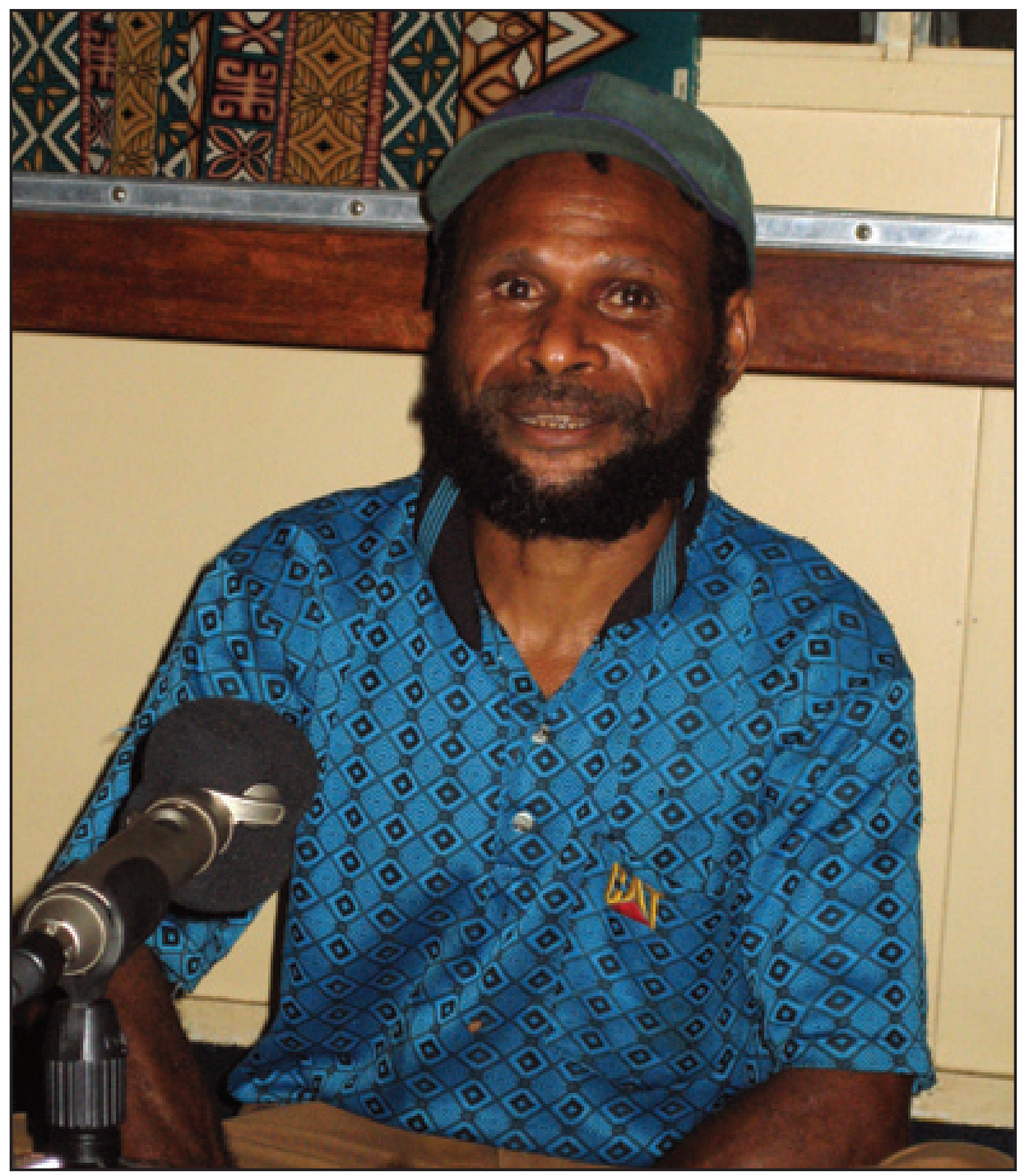

Figure 5. Peter Kerua performing tom yaya kange in Kefamo, June 2006 (photo by author).

Peter Kerua (figure 5), from Kailge in the $\mathrm{Ku}$ Waru area, is adept at two different melodic styles for tom yaya kange. While having learned Pepa's metric melodic style, the original style mastered by Kerua is quite different. He considers this the traditional style of the Kailge area. The following transcription is from a performance that Kerua gave at the Kefamo workshop on chanted tales in 2006 and was recorded by Chris Haskett. It concerns the tribal fighting in his area (figure 6). 
Figure 6. Melody and sustained pitches of Kerua's tom yaya kange. An audio file of this example can be found in online item 24.
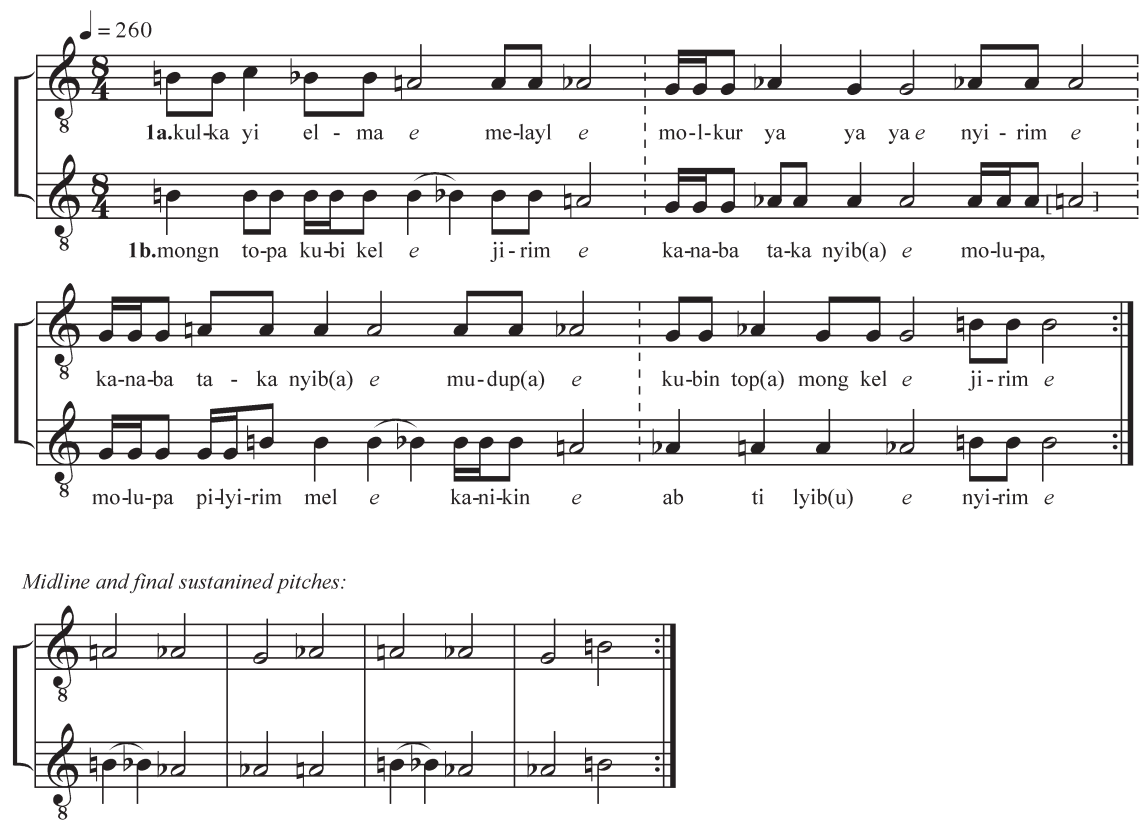

Kerua's opening lines of text, corresponding to one statement of the melody, are as follows: ${ }^{19}$

1a. kulka yi elma $e$ melayl $e$

molkur ya ya ya $e$ nyirim $e$

kanaba taka nyiba $e$ mudupa $e$

kubi-n topa mong kel $e$ jirim $e$

1b. mong-n topa kubi kel $e$ jirim $e$

kanaba taka nyiba e molupa,

molupa pilyirim mel $e$ kanikin $e$

ab ti lyibu e nyirim $e$

19 The transcription and translation of this text are again based on work done by Gomb Minimbi. In this case, however, Rumsey has standardized the orthography - according to that which he and Merlan devised for Ku Waru (Merlan and Rumsey 1991:323-24) — and slightly revised the translation. 
Sung Tales from the Papua New Guinea Highlands

\section{translation:}

1a. a Kulka fighting man

“they all know I'm here," he said

let me silently see what's happening

his nose made his eyes look small

1b. his eyes made his nose look small

let me silently see what's happening

he stayed there and quietly listened

he wanted to marry a woman

Vocables are italicized in the $\mathrm{Ku}$ Waru text, but omitted from the translation. In the text in figure 6, a number of word-final vowels are written in parentheses: for example, nyib(a) and mudup(a) (measures 2 and 3). While in spoken text, these vowels would be pronounced, here they are partially or fully omitted. Such apocope often precedes a vocable, apparently to accommodate the latter. Note also the use of ya ya ya in the second line. These syllables are fairly frequent in $\mathrm{Ku}$ Waru sung tales (in contrast to Melpa kang rom, where they have not been noted) and probably have contributed to the naming of the genre as tom yaya kange. ${ }^{20}$

Kerua's performance lasts just over fifteen minutes. Clearly this is in a very different melodic style, much more chromatic, and also harder to notate easily in Western staff notation since intervals are smaller and less discrete than in the Pepa example. In spite of the limitations of my transcription, it is clear that there are textual lines of eight beats, each characterized by a final vocable sustained through beats seven and eight, and also a midline vocable, held on beats four and five-midline vocables have not been found in the corpus of Melpa kang rom examined to date, but do appear in songs, as in Pepa's amb kenan discussed above. Eight lines of text are set to a binary melody. Hence, vocables account for approximately $50 \%$ of the total length of Kerua's melody. To reflect this structure, I have constructed the time signature as $5+3$, that is, 5 beats accommodate the first part of the text plus vocable, and 3 beats the final text and vocable. Note also the bracket on the final pitch of measure 6 . This is because Kerua takes a breath at this point in the textual fragment given; the pitch here is determined from subsequent repetitions.

As in Pepa's performance, the setting is basically syllabic. In the first halfmelody, both midline and final vocables are each sustained on the same pitch for

20 Melpa kang and Ku Waru kange 'story' are cognates, as are Melpa rom and Ku Waru tom, which seem to be associated with ideas of 'praise, loud, singling out' (Niles 2007:107-8, 115-17). 
two beats (notated as a minim in the transcription). However, in measures 5 and 7 of the second half-melody, the midline vocable is sung to two pitches descending by a step (two crotchets in the transcription). This is a good illustration of the fact that while binary melodies involve the transposition of most pitches, such transpositions are seldom exact, that is, there are often slight, but significant, alterations to the melody.

Hence, while the binary melodic structure of this example is clear, the process of creating such a melody is not simply a straightforward mechanical one of transposition. Personal preference often seems to play a role in the final realization of the melody. This is true of songs in general and it is even more pronounced in the performance of sung tales, where the numerous repetitions almost seem to encourage playing with the melody. The general melodic shape and structure are never varied (except through corrections or "errors," as in the case of Pepa discussed above), but the performer does have some latitude in exactly how he or she sonically realizes these features. Such melodic variation in repetition will be the subject of future research.

To illustrate the structure of Kerua's melody more clearly, the pitches of the vocables (i.e., on beats 4-5 and 6-7) are extracted in the measures at the bottom of the example. Such an extraction has sonic logic too, since these are the pitches sustained the longest amount of time in each measure: the other beats are filled with lexical text, often of much shorter durations. Hence, we can see how the melody of the first bar generally descends, the second ascends, the third descends, and the fourth ascends to a larger interval. In the second half-melody, the general progressions are the same, but transposed a minor second higher and with the slight melismatic movements on beats 4-5 in measures 5 and 7, as described above. ${ }^{21}$

Figure 6 is very similar to a musical transcription presented elsewhere of a performance in 1997 by a woman named Wilya, at Webuyl in the Upper Kaugel area near Tambul (Niles 2007:111, ex. 2). The melodic movement is nearly identical, midline and final vocables occur at the same positions and for the same durations in each line, and the slight melismas on two midline vocables are also duplicated. The recordist, Rumsey, notes that Wilya recounted how she learned the tradition from her mother who would perform such tom yaya kange to her children at night, when they went to sleep with her. She has continued the tradition and her recorded performance was a "dazzling display that was evaluated by [Rumsey's] highly critical male assistants from across the range as the best one we recorded in the Kaugel Valley" (Rumsey 2001:203).

21 The type of melody described here is used in Kerua's performance of the story of Kubu Suwakl, as discussed by Rumsey in chapter 11 . 
Other $\mathrm{Ku}$ Waru performers recorded by Rumsey use the same or a similar binary melody of eight beats per line, with sustained vocables on beats 4-5 and 7-8, and eight lines per melody. This is evident in earlier recordings of Kerua (1997, 2004), as well as in performances by Gabriel Bakari (1997) and Karma (1983). A slight variation on this metric melody is found in performances from 1997 by Engal Kep (Rumsey 2007), Konga, and Philip Win. Each of these performers uses a similar eight-line binary melody, but there are only seven beats per line. Here, while the midline vocable is sustained for beats $4-5$, the terminal vocable only lasts one beat. Thus, this variation in the duration of the final vocable is comparable to that described above for melodies more similar to Pepa's, as performed by Oke-Korpa and Ok Puluyl.

\section{Hagen metric melodies}

Interestingly, $\mathrm{Ku}$ Waru people distinguish two types of ab kunana courting songs. ${ }^{22}$ Pala keripa kunana 'fence-post sharp-point songs' are associated with the cultivated grasslands of the Nebilyer River valley floor to the east and the Melpa region further to the northeast. Musically, this form appears to be identical to Melpa courting songs, such as the one performed by Pepa as a preface to his kang rom: binary melodies involving discrete intervals, "diatonic" melodic movement, and the distinctive leap of a perfect fourth or fifth (as in the first measure of figure 2). Hence, pala keripa kunana are very similar to the melodic style used in Pepa's kang rom.

Additionally, however, there is another type of $\mathrm{Ku}$ Waru courting song called uj ka kunana 'tree vine song'. While not found in the Melpa area, it is shared with the Tambul region to the west and is felt by some $\mathrm{Ku}$ Waru speakers to be their more traditional form in comparison with pala keripa kunana. While $u j k a$ kunana do not always employ binary melodies, when they do, they involve much smaller intervals than pala keripa and more "chromatic" movement. Hence, they are more akin to Kerua's melodic style as described here.

While much more needs to be done on musically distinguishing these $\mathrm{Ku}$ Waru genres from one another, and on their relation to Melpa amb kenan, the evidence does suggest that the metric melodic style described for the sung tale of Pepa (Konts, et al.) can be considered to have originally been associated with the Melpa area, while that described for Kerua (Wilya, et al.) is more linked to the $\mathrm{Ku}$ Waru-Tambul areas.

In spite of the melodic and metric differences highlighted, the Hagen region stands apart from other areas in which sung tales are performed through the use

22 Fuller descriptions with musical examples can be found in Niles (2007). 
of textual lines of fixed metric length, terminated by a vocable, and the setting of these lines to a binary melody that is repeated continuously until the completion of the story. Details, such as the presence or absence of a midline vocable, the duration of vocables, the number of beats per line of text, and the "diatonic" or "chromatic" nature of the melodic movement contribute to the establishment of subgroupings within the Hagen area as a whole. All of these general and more specific features are also present in songs, but with different emphases. Hence, Hagen musical characteristics are very much evident in the metric melodic framework used for the presentation of Hagen sung tales.

\section{Acknowledgments}

I appreciate the assistance of the Australian Research Council, CulturaSenzaFrontiere (Milan), and the Institute of Papua New Guinea Studies which have supported my participation in this project in many ways. In particular, my involvement in the 2004 Goroka and 2006 Kefamo workshops stimulated my attempts to understand sung tales over the whole region and enabled me to discuss the genres with both performers and researchers-truly wonderful experiences.

Memafu Kapera, Acting Managing Director of the National Broadcasting Corporation of Papua New Guinea, kindly gave permission for excerpts of Pepa's performance to be available for download.

Much of the analysis for this paper was done while I was recovering from emergency eye surgery in Brisbane, where I was wonderfully cared for by Gordon and Robina Spearritt. I can never begin to repay their abundant hospitality, generosity, and kindness. They provided an exquisite environment for recovery and my analytical focus.

Andrew Strathern and Pamela Stewart have constantly been supportive of my studies, and their works and comments continue to encourage me. I appreciate their thoughtful comments on an earlier version of this paper. My indebtedness to the translation work of Gomb Minimbi is apparent throughout this paper. Without such assistance, this paper would have taken quite a different form.

Alan Rumsey's enthusiasm for this project has been infectious from the very beginning. Although initially I envisioned my involvement to be quite minimal, Alan's questions, encouragement, and excitement totally drew me into the world of chanted tales. His continued willingness to explore, learn, challenge, and exchange materials and ideas has inspired everyone involved in the project. While many things await further research, I hope our contributions here have begun to demonstrate the great richness of these Highlands traditions. Thank you, Alan, for involving me. 
Sung Tales from the Papua New Guinea Highlands

\section{References}

Mackay, Ian K. 1976. Broadcasting in Papua New Guinea. Melbourne: Melbourne University Press.

Merlan, Francesca, and Alan Rumsey. 1991. Ku Waru: Language and Segmentary Politics in the Western Nebilyer Valley, Papua New Guinea. Studies in the Social and Cultural Foundations of Language, 10. Cambridge: Cambridge University Press.

Niles, Don. 2007. "Sonic Structure in Tom Yaya Kange: Ku Waru Sung narratives from Papua New Guinea." In Oceanic Music Encounters-the Print Resource and the Human Resource: Essays in Honour of Mervyn McLean, edited by Richard Moyle, 109-22. Research in Anthropology and Linguistics Monograph, 7. Auckland: University of Auckland.

Rumsey, Alan. 1995. "Pairing and Parallelism in the New Guinea Highlands." In SALSA II: Proceedings of the Second Annual Symposium about Language and Society, Austin, edited by Pamela Silberman and Jonathan Loftin, 10818. Texas Linguistic Forum, 34. Austin: University of Texas.

2001. "Tom Yaya Kange: A Metrical Narrative Genre from the New Guinea Highlands." Journal of Linguistic Anthropology 11 (2): 193-239.

. 2005. "Chanted Tales in the New Guinea Highlands of Today: A Comparative Study." In Expressive Genres and Historical Change: Indonesia, Papua New Guinea and Taiwan, edited by Pamela J. Stewart and Andrew Strathern, 41-81. Anthropology and Cultural History in Asia and the IndoPacific. Hants: Ashgate Publishing.

. 2006a. "The Articulation of Indigenous and Exogenous Orders in Highland New Guinea and Beyond." The Australian Journal of Anthropology 17 (1): 47-69.

. 2006b. "Verbal Art, Politics, and Personal Style in Highland New Guinea and Beyond." In Language, Culture and the Individual: A Tribute to Paul Friedrich, edited by Catherine O’Neil, Mary Scoggin, and Kevin Tuite, 319-46. Munich: Lincom.

- 2007. "Musical, Poetic and Linguistic Form in Tom Yaya Sung Narratives from Papua New Guinea.” Anthropological Linguistics 49: 237-82.

Stewart, Pamela J., and Andrew Strathern. 2002. Gender, Song, and Sensibility: Folktales and Folksongs in the Highlands of New Guinea. Westport, CT: Praeger. 
Strathern, Andrew. 1983. Review of Oral and Traditional Literatures by Norman Simms. Bikmaus 4 (2; June): 79-80.

Strathern, Andrew, and Pamela J. Stewart. 2005a. "Introduction. In Expressive Genres and Historical Change: Indonesia, Papua New Guinea and Taiwan, edited by Pamela J. Stewart and Andrew Strathern, 1-39. Anthropology and Cultural History in Asia and the Indo-Pacific. Hants: Ashgate Publishing.

_ 2005b. "Melpa Songs and Ballads: Junctures of Sympathy and Desire in Mount Hagen, Papua New Guinea." In Expressive Genres and Historical Change: Indonesia, Papua New Guinea and Taiwan, edited by Pamela J. Stewart and Andrew Strathern, 201-33. Anthropology and Cultural History in Asia and the Indo-Pacific. Hants: Ashgate Publishing.

Vicedom, Georg F. 1937. “Ein neuentdecktes Volk in Neuguinea: Völkerkundliche Beobachtungen an der Bevölkerung des Hagen-Berges im ehemals deutschen Teil von Neuguinea." Archiv für Anthropologie 24: 11-44, 190-213.

Vicedom, Georg F., and Herbert Tischner. 1943-48. Die Mbowamb: Die Kultur der Hagenberg-Stämme im östlichen Zentral-Neuguinea. 3 vols. Monographien zur Völkerkunde, 1. Vol. 1: Hamburg: Cram, de Gruyter, 1943-48; vol. 2-3: Hamburg: Friederichsen, de Gruyter, 1943.

1977. Myths and Legends from Mount Hagen. Translated by Andrew Strathern. Boroko: Institute of Papua New Guinea Studies. [abridged translation of Vicedom and Tischner 1943-48, vol. 3] 